\title{
Recent sediments: environmental chemistry, ecotoxicology and engineering
}

\author{
Christian Bogdal $^{1,2}$ • Aurea C. Chiaia-Hernández ${ }^{3}$ - Walter Giger ${ }^{4}$
}

Received: 13 April 2016/Accepted: 17 April 2016/Published online: 20 May 2016

(C) Springer-Verlag Berlin Heidelberg 2016

At the bottom of surface waters, such as lakes, slowly flowing or dammed rivers, estuaries and oceans, the continuous deposition of suspended particulate matter leads to the formation of new sediment layers. Because of the tendency of many organic and inorganic pollutants to sorb onto surfaces and partition into organic-rich phases, sediments represent a significant and often final sink for many chemicals in the environment.

If the sediment layers are not disturbed by bioturbation or resuspension, sediment cores provide precious archival information on input changes of environmental pollutants under the condition that the latter are sufficiently stable (Heim and Schwarzbauer 2013). Such sedimentary records are investigated by environmental scientists in interdisciplinary efforts. Earth scientists (sedimentologists) identify ideal sampling sites, analyse sedimentation regimes and provide reliable dating of the sediment layers (Rothwell and Rack 2006). Analytical chemists are challenged to identify and quantify trace pollutants in the complex sample matrix of the sediment material (Clement et al. 2001). Environmental chemists evaluate the distribution of contaminants between sediment surfaces and aqueous phases. Microbiologists evaluate the impact and mechanisms of aerobic and anaerobic biotransformation

Responsible editor: Philippe Garrigues

Walter Giger

giger@giger-research.ch

1 Institute for Chemical and Bioengineering, Swiss Federal Institute of Technology (ETH Zurich), CH-8093 Zürich, Switzerland

2 Institute for Sustainability Sciences (ISS), Agroscope, CH-8046 Zürich, Switzerland

3 Swiss Federal Institute of Aquatic Science and Technology (Eawag), CH-8600 Dübendorf, Switzerland

4 Giger Research Consulting, CH-8049 Zürich, Switzerland processes occurring in sediments (Boxall et al. 2004; Vazquez-Duhalt 2008). Ecotoxicologists assess the impact of contaminated sediments on aquatic ecosystems and associated risks for human exposure (Escher and Hermens 2002).

Contaminants enter lake systems and their sediments through different processes and at different concentration levels (Walling 2005). On the one hand, the chronic contaminant inputs to sediments at trace levels occur very widely from regional to global scales with riverine, run-off and atmospheric input pathways. On the other hand, continuous point sources, such as harbour activities or waste discharges and accidents, e.g. oil spills or fires, can result in a severe degree of contamination in sediments. Much experience exists in treating heavily contaminated sediments, but remediation of sediments containing background-level contaminations is still an unresolved issue requiring innovative engineering techniques (Ghosh et al. 2011).

Recent progress in the performance, handling and speed of analytical methods opened new opportunities for the quantification and interpretation of chemical tracers in sediments. Lateral distributions in surface sediment contaminants represent an innovative tool for source apportionment of pollution. In addition, dated sediment cores reflect changes in the chemical inputs and, thus, provide an instrument for the assessment of the effectiveness of chemical regulations. Also, the magnitude and impact of climate warming can be decoded from sedimentary records.

Sediments represent dynamic systems affected by hydrodynamic factors (storms, subaquatic slumps), chemical processes (sorption, redox reactions) and microbial transformations. A correct evaluation of these processes is crucial for the prediction of the long-term fate of chemical pollution in sediments and for performing comprehensive environmental risk assessments. Compared to established standards for water, air and soil quality, the ecotoxicological thresholds for polluted sediments are poorly defined in national and international 
legislation (Ortega-Calvo et al. 2015). Advancing the interdisciplinary science of contaminated sediments is, therefore, of high societal relevance.

For this special issue of ESPR, entitled "Recent sediments: environmental chemistry, ecotoxicology and engineering", contributions were solicited from those experts, who had made an oral or poster presentation at the Contaminated Sediments (ContaSed) Conference, held at the ETH Conference Center Stefano Franscini, Monte Verità, Ascona, Switzerland, from March 8 to 13, 2015 (Chiaia-Hernandez and Giger 2016). In addition, scientists working in the field of sediment pollution worldwide were invited to report on their most recent research.

This special issue contains a collection of 24 articles, in which the authors present and discuss their latest findings about interesting and challenging cases, novel approaches and new remediation concepts relevant to contaminated sediments. This updated compilation of knowledge is addressed to the broader scientific community interested in environmental issues. The articles in this special issue are grouped into three sections as described below. Full article titles are provided in the table of contents.

\section{Environmental chemistry and monitoring}

Eleven publications report on studies about the occurrence of trace micropollutants and the identification of their sources and fate in sediments. Targeted pollutants include legacy organochlorine compounds, brominated flame retardants, natural steroid hormones, plasticizers, fluorinated surfactants, alkylphenols, pyrethroid insecticides, polycyclic aromatic hydrocarbons and trace metals.

\section{Ecotoxicology and risk assessment}

Nine articles deal with the topics of toxic effects and ecological risk assessment of contaminated sediments. Cases of sediments polluted by organic micropollutants and trace metals from diffuse sources as well as heavy contamination by mercury and organochlorine compounds from chlor-alkali electrolysis and by fluorinated surfactants from the fluorochemical industry are covered.

\section{Engineering}

Four papers report on alternative remediation approaches for contaminated sediments. Method developments at laboratory scale for electrokinetic remediation of sediments contaminated by heavy metals as well as for bio- and phytoremediation of sediments polluted by hydrocarbons are presented.
The guest editors sincerely thank all contributing authors and the independent anonymous reviewers for their respectable efforts. The ESPR Editor-in-Chief Philippe Garrigues, the handling Editors as well as the Editorial Assistants Géraldine Billerot, Laure Beugnot and Dennis Villahermosa are acknowledged for their support during the preparation of this special issue.

\section{References}

Boxall ABA, Sinclair CJ, Fenner K, Kolpin D, Maund SJ (2004) When synthetic chemicals degrade in the environment. Environ Sci Technol 38:368A-375A

Chiaia-Hernandez AC, Giger W (2016) International Conference on Contaminated Sediments-ContaSed 2015. Environ Sci Pollut Res. doi:10.1007/s11356-016-6700-7

Clement RE, Yang PW, Koester CJ (2001) Environmental analysis. Analyt Chem 73:2761-2790

Escher BI, Hermens JLM (2002) Modes of action in ecotoxicology: their role in body burdens, species sensitivity, QSARs, and mixture effects. Environ Sci Technol 36:4201-4217

Ghosh U, Luthy RG, Cornelissen G, Werner D, Menzie CA (2011) In-situ sorbent amendments: a new direction in contaminated sediment management. Environ Sci Technol 45:1163-1168

Heim S, Schwarzbauer J (2013) Pollution history revealed by sedimentary records: a review. Environ Chem Lett 11:255-270

Ortega-Calvo JJ et al. (2015) From bioavailability science to regulation of organic chemicals. Environ Sci Technol 49:10255-10264

Rothwell RG, Rack FR (2006) New techniques in sediment core analysis: an introduction. In: Rothwell RG (ed) New techniques in sediment core analysis, pp 1-29

Vazquez-Duhalt R (2008) Special issue: environmental biotransformations. J Mol Microbiol Biotechnol 15:67-219

Walling DE (2005) Tracing suspended sediment sources in catchments and river systems. Sci Total Environ 344:159-184

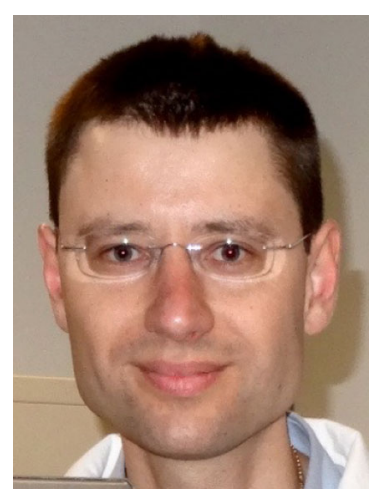

Christian Bogdal received a doctoral degree in chemistry from ETH Zurich, the Swiss Federal Institute of Technology in Zurich, Switzerland. Currently, he is a senior scientist and lecturer at ETH Zurich and a research associate at the institute Agroscope. In his scientific projects, he investigates emissions, reservoirs, mass fluxes and long-term fate of persistent environmental contaminants in the environment. He applies advanced trace analytical methods to monitor temporal and special trends of environmental pollutants. He combines the experimental measurements with chemical fate modelling to describe the behaviour of environmental contaminants on a regional and global scale. The chemicals in his main interest include legacy persistent organic pollutants, emerging organohalogen compounds and mercury. 


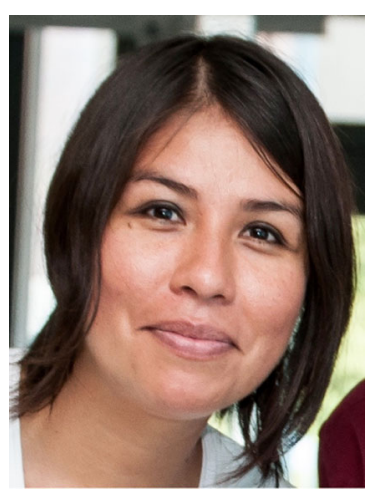

Aurea C. Chiaia-Hernández earned her master degree in chemistry from Oregon State University in Corvallis, USA followed by a doctoral degree in environmental sciences from ETH Zurich, the Swiss Federal Institute of Technology in Zurich, Switzerland. In the year following graduation, she has been a research scientist at ETH Zurich. Currently, she works at Eawag, the Swiss Federal Institute of Aquatic Science and Technology, where she studies the fate and behavior of organic contaminants in natural systems, especially in soils and sediments. Additionally, her research interests include the development of analytical methods for the quantitative determination of organic micropollutants and their transformation products, for the identification of suspect and non-target screening by LC-HRMS and the evaluation of effects and exposure of organic contaminants to the environment.

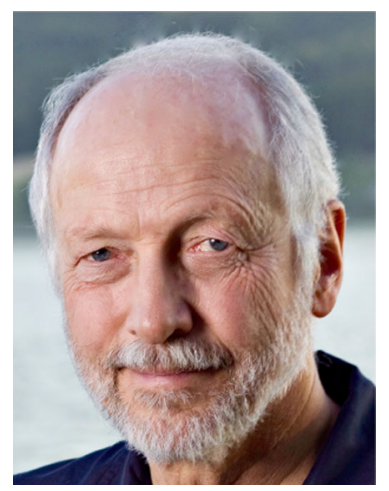

Walter Giger holds a PhD degree in chemistry from ETH Zurich, the Swiss Federal Institute of Technology in Zurich, Switzerland. He is a Scientist Emeritus at Eawag, the Swiss Federal Institute of Aquatic Science and Technology, and a Professor Emeritus at ETH Zurich. He is an expert on organic contaminants in the aquatic environment and in the evaluation of chemical, physical and biological processes determining the environmental fate of chemicals.

Between 1990 and 2007 Walter Giger was Associate Editor of the journal Environmental Science and Technology published by the American Chemical Society. From 2009 to 2014, Walter Giger was chairing the Division of Chemistry and the Environment of the European Association of Chemical and Molecular Sciences (EuCheMS) and he is Consulting Editor of the journal Environmental Science and Pollution Research. Walter Giger was appointed as a Highly Cited Researcher in the field of Environmental Sciences. In 2008 the American Chemical Society named him a Legend of Environmental Chemistry and the journal Environmental Science and Technology honoured him with a Tribute Issue. 